\title{
Study on the Cultivation Mechanism of the Energy Chemical Engineering Talents from the Perspective of International Comparison
}

\author{
Xiaoli Wang ${ }^{1,2, *}$, Fang Zhang ${ }^{1,2}$, Gongde $\mathrm{Wu}^{2}$ \\ ${ }^{1}$ School of Environment and Technology, Nanjing Institute of Technology, Nanjing, China. \\ ${ }^{2}$ Energy Research Institute, Nanjing Institute of Technology, Nanjing, Jiangsu, China \\ *Corresponding author
}

Keywords: Cultivation Mechanism; Energy Chemical Engineering; International Comparison.

Abstract: In order to solve the current problems existed in the cultivation mechanisms of applied energy chemical engineering talents, a comparison study on the education mode, teaching staffs, professional courses and practical teaching was carried out between the status at home and abroad. Moreover, we proposed the characteristics of applied energy and chemical talents from the perspective of international comparison. Furthermore, an appropriate cultivation mechanism for the applied energy chemical engineering talents of Jiangsu province was build up.

\section{Introduction}

In the Outline of "the National Medium and Long Term Science and Technology Development Plan (2006-2020)" and "the National 13th Five-Year Plan", energy conservation, environmental protection and new energy industries were listed as strategic emerging industries. As we known, Jiangsu province is a major chemical, energy and power province in China. According to statistics, there are more than 5000 chemical enterprises and nearly 200 coal-fired power plants in Jiangsu Province (data from the network). In recent years, the growth rate of energy and chemical industry in Jiangsu Province has been higher than GDP growth rate. Energy chemical technology and other science and technology derived from it are playing a huge role in social development and scientific and technological progress. At present, there is an urgent need for a large number of senior professionals with knowledge of clean energy conversion, coal chemical industry, comprehensive utilization of power plant chemistry, environmental catalysis, green synthesis, new energy utilization and chemical conversion, which poses great challenges to higher education.

On the other hand, under the background of economic globalization, China's higher education must train high-quality talents with innovative spirit and practical ability to meet the needs of contemporary economic and social development. With more and more Chinese enterprises expending to the world, much efforts have been paid to cultivate a large number of talents with international vision, understanding of international rules and professional knowledge of energy and chemical industry. Jiangsu province is an early province to open to the outside world, and also a large open economy province. The rapid development of Jiangsu's foreign-related economy 
undoubtedly needs more internationalized applied energy and chemical talents, and the training task should be fulfilled by Jiangsu universities. Therefore, how to build an internationalized talent training mechanism for energy and chemical engineering in order to better serve the development of Jiangsu's social economy has become an urgent problem to be solved by Jiangsu education administration department and Jiangsu universities.

\section{A Comparative Study on the Cultivation Mechanism of Applied Energy and Chemical Talents at Home and Abroad}

\subsection{Comparison of Educational Modes}

Overseas education models of energy and chemical industry also differ from each other. Japan is one of the countries with higher modernization. Its education model emphasizes "wide caliber", and mathematics, physics, computer, energy and chemical industry and other aspects of knowledge are often seen as an organic whole. The United States promotes "multi-level" energy and chemical education, including undergraduate, graduate and vocational education. Modularization is the feature of the curriculum of energy and chemical engineering education in Britain. In Germany, the "dual system" of education is prominent. According to the survey, less than $20 \%$ of the employed population in Germany in 2014 had received higher education, while moreover two-thirds had received the "dual vocational education"[1-2]. The education of energy and chemical industry in China has no obvious characteristics. Undergraduate education is still dominated by theoretical courses and theoretical education, and the curriculum system is not perfect yet. Most universities determine the curriculum structure according to the background or abilities of teachers. Higher vocational education is equivalent to reducing the standard of undergraduate education with less theoretical knowledge, but the practical ability has not been improved. The actual production and operation of China's energy and chemical enterprises are very little known, very strange, and theory and practice are seriously disconnected.

\subsection{Comparison of Teaching Staff}

Teachers of energy and chemical engineering education abroad often need higher educational qualifications and rich experience in practical work. The minimum academic qualifications of theoretical teachers in German vocational schools are undergraduate courses $(50 \%$ of the teachers in some schools have doctoral degrees). A qualified teacher needs at least two years of practical work experience in his major, passing two national examinations, two years of probation period, 25 hours a week in the classroom teaching. German teaching attaches great importance to the cultivation of students' practical ability. In addition to general professional course teachers, there are also specialized practical course teachers in Lehak Campus of Bafu State Cooperative Education University in Germany. These teachers need additional special qualifications, such as more than five years of formal working experience in enterprise. In contrast, teachers of energy and chemical engineering specialty in China have a complicated structure, lower educational level and less practical experience [3-5].

\subsection{Comparison of Course Settings}

The curriculum of energy and chemical industry abroad is generally based on the elements of energy and chemical industry. Typical courses include energy technology, chemical thermodynamics, etc. Emphasis is placed on global or regional expertise and case-based teaching. In China, the specialty settings of schools often have their own emphases according to their own industry background, and curriculum system lack strategic courses and extended research courses. 


\section{Research on the Characteristics of Applied Energy and Chemical Talents from the Perspective of International Comparison}

\subsection{Internationalization Characteristics}

The internationalization characteristics of energy and chemical talents can be reflected in the following aspects: firstly, they have good psychological quality and the ability to adapt to the survival and development of foreign energy and chemical industries; secondly, they have broad internationalization vision and internationalization thinking mode, and can think about energy and chemical engineering specialty from the perspective of global resource allocation. Thirdly, they are also familiar with international energy and chemical related laws and regulations, and often show strong international activities ability. Fourth, they are proficient in an international language with strong cross-cultural communication skills. Fifth, they possess the experience in studying, practicing or working in a foreign energy industry. Sixth, they are familiar with the international knowledge of energy and chemical industry, which can be acquired in domestic colleges or universities.

\subsection{Applied Traits}

Generally speaking, the development of energy and chemical industry needs two kinds of talents, theoretical research type and practical application type. Among them, the demand of practical talents is much higher than that of theoretical talents. Based on the above analysis, it is found that applied talents refer to those who can adapt to the needs of the development of energy and chemical industry, apply their knowledge and skills to the field of energy and chemical industry, and create social value through practice [6].

\subsection{Compound Characteristics}

Based on the above analysis, the applied energy and chemical talents in the perspective of international comparison are the combination of internationalization and applied type. This kind of energy and chemical talents not only has the internationalization characteristics of energy and chemical talents, but also belongs to the applied energy and chemical talents. Therefore, such talents may be both internationalized elite talents with strong practicality and internationalized professionals with strong professional technology. Of course, the applied talents always occupy an absolute share of the energy and chemical talents market in both international talent market and domestic talent market.

\section{Analysis of Problems in the Cultivation Mechanism of Applied Energy and Chemical Talents in Jiangsu Province}

\subsection{Problems of the Operating Mechanism}

The key to the internationalization of education lies in the establishment of cooperative sharing mechanism and the integration and utilization of complementary resources of universities, scientific research institutes and enterprises at home and abroad. In order to realize the integration and sharing of energy and chemical resources, it is necessary to build a corresponding sharing and collaboration mechanism. However, in fact, there is still a lack of resources integration platform for internationalization of education, and the corresponding sharing and collaboration mechanism has not yet been established. For example, the cooperation mechanism among the foreign or domestic universities and enterprises (foreign or domestic), which are conducive to the cultivation of internationalized applied energy and chemical talents, has not been built up [8]. To find a way of internationalized inter-school integration, industry-university-research cooperation and 
school-enterprise cooperation, Chinese universities need coordinated reform and resource integration between educational administrative departments and universities in many aspects, so as to promote the effective use of complementary international educational resources.

\subsection{Problems of the Development Mechanism}

At present, the development of internationalized education in different levels of universities in China is unbalanced, which is manifested in three aspects: firstly, the key research universities, such as Tsinghua University, have developed rapidly in the field of internationalization education, and their subject areas are approaching the international frontier. However, the development of internationalized education in other universities is relatively slow, and the gap is large[9]. Secondly, they are also undergraduate colleges of teaching and research type, and private-funded universities, which lag behind the level of international education development of public undergraduate colleges and universities. Thirdly, the level of international education development of higher vocational colleges is generally low. Because the demand of foreign-related enterprises and institutions for internationalized applied energy and chemical talents is classified by different levels, the educational administrative departments should not only strengthen the cultivation of high-end internationalized applied energy and chemical talents, but also construct a hierarchical and classified training mechanism to promote the balanced development of internationalized education. Only in this way, the quality level of international education of energy and chemical engineering could be enhanced.

\subsection{Problems in the Management System}

The training of internationalized applied energy and chemical talents needs to rely on a perfect management system to develop rapidly. In recent years, for promoting the process of internationalization of education, the educational administrative departments have made relevant reforms and achieved gratifying results in the reform of the educational system. However, there are still some problems in the relevant policies and systems to promote the development of internationalized applied energy and chemical talents, such as the authority of specialty setting, the way of running school, the setting of the enrollment and examination system, and the setting of the internal operating mechanism of the relative balance between administrative power and academic power [10]. Only by reforming those relevant mechanisms at the management level can universities establish management systems and operational mechanisms.

\section{Research on the Construction of Jiangsu Applied Energy and Chemical Talents Cultivation Mechanism from the Perspective of International Comparison}

The coordinated integration of educational resources for energy and chemical engineering requires the joint efforts of educational administrative departments and universities. For the administrative departments of education, we should mainly construct two kinds of synergy mechanism: one is to construct the synergy mechanism of talent supply and demand. If there is a contradiction between the demand and supply of energy and chemical talents, it is necessary for the administrative department of education to construct an information sharing platform for the demand and supply of talents, so as to effectively solve the problem of dislocation between supply and demand of internationalized and applied energy and chemical talents. The second is to build a synergetic mechanism for international cooperation, and to set up an international energy and chemical resources synergistic platform for exchanges and cooperation between domestic and foreign universities.

For colleges and universities, the construction of synergy mechanism should focus on the construction in the fields of inter-school, industry, university and research. From the national point 
of view, the construction of inter-school coordination mechanism refers to the construction between domestic and foreign universities. From the content point of view, it mainly includes the construction of cooperative mechanisms such as cooperative energy and chemical school-running projects, scientific research cooperation, academic exchanges and visits between teachers and students. In order to highlight the characteristics of internationalized applied energy and chemical talents, universities and employers should establish a cooperative mechanism of production, education and research.

\section{Acknowledgement}

The authors acknowledge the financial supports from the Project of Higher Education Research at School Level of Nanjing Institute of Technology (2016ZC19).

\section{References}

[1] S. L. Wu, F. H. Li. Shandong Chemical Industry, 2016, 45: 97-98, 100.

[2] Y. C. Wang, Y. B. Xue, X. X. Wang, B. D. Dai. Education Modernization, 2019, 35: 31-33.

[3] J. F. Rong, M. G. Chen, M. Liu, S. S. Wu, Y. Zhang. Guangzhou Chemical Industry, 2016, 44:218-219.

[4] C. J. Ding. Chemical Enterprise Management, 2018, 26: 122-122.

[5] Z. Lei, Y. H. Tang, J. Zhang, S. Q. Liu. Guangdong Chemical Industry, 2019, 46: 252-253.

[6] B. Liu, Q. Fu, X. H. Bao, Z. Q. Tian. Science China Press: Chemistry, 2018,48:1-8.

[7] G. Q. Huang, S. M. Zhong. Chemical Enterprise Management, 2019, 20-21.

[8] H. Zhao, J. Liu, Y. N. Dong, W. Niu, S. S. Li, X. G. Bi. Journal of Shenyang Institute of Engineering (Social Sciences), 2015, 11:547-550.

[9] F. Wang, P. He, Q. L. Liao, J. S. Liu, H. C. He. Journal of Higher Education, 2016, 7: 183-184.

[10] H. Zhao, J. Q. Liu, J. Liu, X. G. Bi. Guangdong Chemical Industry, 2015, 42:261-262. 